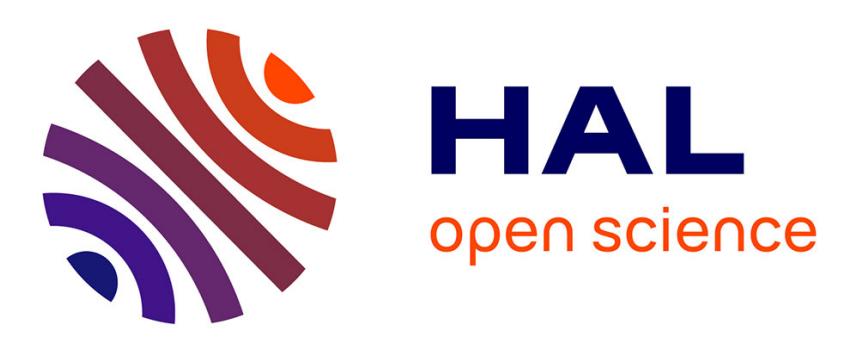

\title{
Does AIDS involve some collusion by the neuro-immune system because of positive learning of the disarmament strategy? \\ Patrick Sandoz
}

\section{- To cite this version:}

Patrick Sandoz. Does AIDS involve some collusion by the neuro-immune system because of positive learning of the disarmament strategy?. Medical Hypotheses, 2013, 80, pp.345-351. 10.1016/j.mehy.2012.12.014 . hal-00982819

\section{HAL Id: hal-00982819 https://hal.science/hal-00982819}

Submitted on 24 Apr 2014

HAL is a multi-disciplinary open access archive for the deposit and dissemination of scientific research documents, whether they are published or not. The documents may come from teaching and research institutions in France or abroad, or from public or private research centers.
L'archive ouverte pluridisciplinaire HAL, est destinée au dépôt et à la diffusion de documents scientifiques de niveau recherche, publiés ou non, émanant des établissements d'enseignement et de recherche français ou étrangers, des laboratoires publics ou privés. 


\section{Does AIDS involve some collusion by the neuro-immune system because of positive learning of the disarmament strategy?}

Patrick SANDOZ, PhD

Institut FEMTO-ST, Université de Franche-Comté, UMR CNRS 6174,

24, rue de l'Epitaphe, 25000 Besançon, France

Phone : +33 381666420 - Fax : +33 381666700

E-mail : patrick.sandoz@univ-fcomte.fr

\section{Abstract}

Korzybski's general semantics recommends considering living beings as organisms-as-a-whole in their environment. Our cognitive abilities, specific to the human species, have thus to be taken into account. In this framework we establish a semantic similarity between particular stressful events of the $20^{t h}$ century and AIDS in which the immune-deficiency-caused is semiotically seen as a biological state of disarmament of the organism. It then appears that :

- at the extent of the worldwide propagation of the pandemic, the disarmament concept was valued as a hopefully survival strategy because of the media coverage of the Cold War and of the associated threat of nuclear annihilation,

- at the extent of the African regions of origin of the different HIV strains, the best survival behavior of slaves fit the disarmament concept.

These observations suggest that AIDS could benefit from some collusion by the neuro-immune system because of positive learning of the semiotic concept of disarmament, thus making the terrain favorable to the germ in response to intense stress. The disease would then result from a conditioning process based on semiotics and involve some confusion at the level of the unconscious cognitive system between disarmament toward outside the body and disarmament toward inside the body. This hypothesis is discussed within a multidisciplinary perspective considering the specificities of our modern lifestyles, the cybernetic ability of signs to control metabolism and behavior, and the recent advances of epigenetics and cognition sciences. This hypothesis may explain the multiple cross-species transmissions of the immunodeficiency virus into humans during the $20^{\text {th }}$ century. Further research is suggested for evaluating this hypothesis.

Key-words : HIV-AIDS, adaptation, semiotics of stress, disarmament concept, cognitive system, Lamarkian mechanism, embodied cognition, levels of abstraction, metaphoric thought, conceptual blending. 


\section{Introduction}

The existence of a new pandemic called AIDS (Acquired Immuno-Deficiency Syndrome) can be linked to the American CDC (Center for Disease Control and Prevention) declaration of June $5^{\text {th }}$, 1981. The latter followed a sharp increase in the reported cases of Pneumocystis carinii and of Kaposi's sarcoma, diseases that especially affect immunodeficient people. The HIV (Human Immunodeficiency Virus) was then rapidly identified as responsible for AIDS [1,2]. However the beginnings of this disease date back to times much earlier than its observation and the discovery of the virus. Numerous scientific works, based on conserved samples [3,4] or on the analysis of the genetic diversity of the viral strains [4-9], allowed the reconstitution of the pandemic genesis. Current knowledge states that multiple HIVs (HIV-1 and HIV-2, with different groups and sub-groups) result from many transfers and adaptations in humans of simian immunodeficiency viruses (SIV) [6, 8, 10-13]. The appearance of the first HIV-1 able to propagate in humans is dated around $1930( \pm 20$ years $)[5,9]$ whereas the oldest human sample infected by HIV dates from 1959 [3]. It is also established that SIVs have existed for thousands of years and that the hunting and butchering of monkeys resulted in many cross-species transmission opportunities of SIVs to humans across the past centuries [14-16]. This context leads to the paradox that humans were in contact with SIVs for many centuries without any viable transmission whereas during only the $20^{\text {th }}$ century, around ten SIV strains were successfully transmitted into humans $[8,10,12,13,17]$. These sudden crossings of the species barrier within a short period of time are still not clearely understood but socioenvironmental arguments have been suggested : non-sterile vaccination campaigns, sexuality and hunting [12,18].

In this paper, we consider the socio-environmental context of the propagation and of the emergence of AIDS within a multidisciplinary approach and in relation to the main disease effect : immunodefficiency. The aim of the immune system is to protect the "self" against any "non-self" aggressions which threaten to disturb homeostasis. From a semantic perspective, the "self" can be identified as the biological territory of the individual. In the case of immunodeficiency, the organism is disarmed, unable to protect itself against "non-self" aggressions. Using a different language register, immune deficiency corresponds to a state of biological disarmament of the organism. It then striking to observe that this semiotic concept of disarmament is shortly related to the major steps of the disease development :

- The worldwide propagation of the pandemic occurred soon after that the disarmament concept was valued as a hopefully survival strategy because of the media coverage of the Cold War and of the associated threat of nuclear annihilation.

- The HIV-1 emerged in western Africa soon after an intense episode of slavery [12,18] in which the renunciation to defend oneself was experienced as the best survival strategy under the submission conditions imposed by the masters. The HIV-2 emergence is also related to a war context $[6,19]$. 
A striking semiotic similarity is thus highlighted between the main effect of AIDS and the nature of the stress imposed by the specific socio-environmental conditions of the emergence and propagation of the disease. The question is then to determine whether this similarity is caused by chance or if it involves some collusion by the neuro-immune system in a way that is specific to the cognitive abilities of the human brain. The facts reported in this paper do not provide any evidence of the existence of such a semiotic mechanism but justify the scientific consideration of this hypothesis. We discuss this question with respect to current biological knowledge. We suggest further research for addressing definitely this possibility that may concern AIDS as well as various other human dysfunctions.

\section{Multidisciplinary approach and context}

\section{Considering the organism-as-a-whole in its environment}

Thirty-five years ago, Engel [20] expressed the need for a new medical model with an extended disease definition (wider than measurable biological quantities and their distance from the norms) and called for a biopsychosocial approach more relevant to the human experience. This claim finds a theoretical explanation in general semantics as established by Korzybski [21] and published as early as 1933. According to Korzybski, each discipline corresponds to a particular level of abstraction. The latter defines the discipline's domain of relevance when the underlying assumptions are met. Words are not the things they refer to and no scientific description will ever be the event it explains. The principles established in the different scientific domains are of great interest for generalization. Any generalization assumes however some simplification and is only applicable to theoretical events that do not exist in empirical reality. For Korzybski the value of a science lies in its ability to provide a similar structure to that of empirical facts. Having integrated the main implications of Einstein's work and of quantum mechanics, Korzybski considers every human experience as a single event taking place in a four-dimensional space-time continuum and whose attributes cannot be definitively listed. Every organism reacts as an organism-as-a-whole tied to its environment. Every human experience constitutes a single event specific to a single space-time instant.

The confusion among the levels of abstraction and the oversight of their intrinsic inability to describe completely any empirical event are responsible for the sometimes contradictory conclusions of different scientific disciplines. For instance at the genetic level, every individual is different and DNA sequences are used as ultimate references in case of doubt about a family link or in a criminal investigation. At the level of the individual, every human being is also different through his appearance, his tastes, his vulnerability or his resistance to pathogens and to life challenges, etc. Biometry is indeed more and more popular as a mean of securing individual identification. On the contrary, at the level of infectious disease, human beings are similar - or even identical - 
in the physiological process by which the pathogen substance makes them ill. The contradiction between these unique and identical attributes is only superficial. It is relative to the different levels of abstraction considered. Korzybski explains that any life event, "necessarily unspeakable", is a single combination of all these levels of abstraction. Thus from the general semantic perspective, the words ascribed to Pasteur at the end of his life - "Terrain is everything, the germ is nothing" - are a typical example of a semantic confusion leading to an impasse. The germ and the terrain correspond to different levels of abstraction, interacting with each other within the organism-as-a-whole, to induce - or not - a disease, as is commonly observed in medical practice.

\section{The ability of signs to control physiology and behavior}

From the perspective of species evolution, natural selection favors the biological characteristics that provide an advantage with respect to environment and life conditions. A semiotic relationship is thus established between selected characteristics and the advantages that they provide, this semiotic relationship being specific to the conditions that determine the selection factors. Semantics is thus intrinsically relevant to living systems because of the process of natural selection.

Since the work of Pavlov [22], we know that after the conditioning of a superior animal like a dog, behavioral (motricity) as well as metabolic (salivary gland secretion) reactions can be switched on and off by means of a wide diversity of signs. Signs have thus the cybernetic ability to control animal activity; this ability being either an innate or a learned process. Let's consider an example : the fox odor is known to trigger an innate reaction of stress and flight in mice; laboratory mice included [23]. During evolution, the predator odor became integrated in the species as a sign of emergency and of risk of death. The advantage of this adaptation is obvious. By reacting to the first sign of predator proximity - its odor - the mouse's flight is anticipated and its chance of survival is increased. This example shows the main role played by semiotics in life systems. The mouse reacts to a sign - the fox odor - that carries a biological significance of risk of death. The sign is identified as the risk itself and triggers the same reactions in the animal and this provides an adaptive advantage. But in the unnatural environment experienced by a laboratory mouse, the fox odor is artificial and no longer signifies the presence of a predator. The identification of the sign with the danger is thus invalid and the innate mouse reaction becomes irrelevant. The biological resources involved in the mouse's reaction to the signal do not provide any advantage. If the signal lasts for a long time, the continued stress state may induce pathological consequences in the animal.

\section{The case of humans in modern times}

In the case of humans, the issue of semiotics and cybernetics is especially important for at least two reasons. Firstly, the specificities of our nervous system make us different to any other species because of our enormous 
capacity for the conscious and unconscious use of signs. A human being is able to abstract over a huge number of levels unlike animals that are limited by their nervous systems to only a few [21]. Secondly, in western countries and in a time period of only a few generations, manufactured products and information technologies have deeply transformed our lifestyles. From a biological perspective, these high-tech communication and information networks form an out-of-body extension of our sensory system. Through modern communication devices we can now perceive events occurring on the other side of the world. For instance, after the earthquake of March $11^{\text {th }} 2011$, Japan was devastated by a tsunami that caused the death of almost 20,000 people. Outside Japan, hundreds of millions of people participated in this remote tragedy. Sadness, compassion, solidarity, etc., but also fear, feelings of vulnerability and helplessness, etc... everyone experienced their own emotional reactions. In such cases, communication networks trigger actual neuro-semantic reactions since through the emotions experienced, the nervous system of each observer is affected by the images of a remote catastrophe. Because of this technological extension of our sensory abilities, the number of tragic events with which our nervous system is confronted is significantly enlarged while usually our actual life conditions are not affected by them at all. This new context of experience may modify our views of the outside world as well as our behaviors [24, 25]. As far as we know, the consequences of this kind of exposure to a continuous flow of information remain mostly unknown. However, the existence of neurological mechanisms such as mirror neurons [26-28] that are activated by one's own action or by the same action executed by someone else suggests that the nervous impact of remote tragic events may be significant. In comparison with the huge number of generations necessary to integrate environmental changes in the gene pool, the technological transformation of our lifestyles has been almost instantaneous. In a similar way to the laboratory mouse exposed to the fox odor, we perceive daily a lot of information that is disconnected from our actual life conditions. Our remote ancestors who passed on their biological "know-how" had never been exposed to so many triggers. Furthermore, all triggers they experienced did have an actual local impact and significance, contrary to the information that we absorb today from the other side of the world. What about the propagation and the effects of this information throughout the nervous system and the human body? Since what is provided by high-tech communication networks corresponds exactly to the main function of the nervous system - to perceive - it would be striking if it did not make some use of the information that is now available.

The theory of general semantics introduced by Korzybski provides a theoretical basis for this study through the definition of the neuro-linguistic and neuro-semantic issues specific to the human language. This challenge results particularly from the "multiordinality" of words whose meaning depends on the context and from the numerous levels of abstraction that can be a source of confusion. Korzybski considers that the structure of the human nervous system creates a bottom-up hierarchy of levels of abstraction. This hierarchy starts from the "unspeakable" sensory perceptions of the most archaic level of the contact with the external world and goes 
up to mental representations and imaginary speculations. The natural and adaptive function of the nervous system assumes that these levels of abstraction follow this bottom-up order; from the most archaic to the most elaborate; i.e. from sensory perceptions to mental abstractions [21,29]. According to Korzybski, the reverse process (top-down) is a source of maladjustment in the individual with many serious potential consequences. Since modern communication networks correspond precisely to this reverse process, it is important to explore their potential impact on human beings.

\section{Recent advances}

The modern synthesis of the laws of heredity, adaptation and evolution [30], which assumes that chance generates genetic diversity and that natural selection favors the most adaptive solutions, is no longer effective at explaining some scientific observations [31-36]. During the last decade, epigenetics has established much evidence of this ineffectiveness of the modern synthesis for questions concerning transgenerational transmission [37-42], the influence of the environment [43-47], the impact of chemical substances $[48,49]$ with consequences for behavior [50-52] or for the risk of disease [53-58].

With all the recent conclusions of epigenetics, a complex and subtle perspective now exists for all enquiry dealing with heredity, adaptation and evolution as well as with the impact of conditions at different stages of life, the effects of stress and the roots of diseases [59,60], etc. The reactivation of these issues that were considered in too restrictive a way during the $20^{t h}$ century is confirmed by other approaches [61,62] and disciplines, for example psycho-neuro-endocrino-immunology [63-65], neurosciences [66-69], psychology [70,71] or psychogenealogy [72,73].

Semiotics is involved in different ways in current research and in scientific enquiries. For instance, in placebo and nocebo effects, signs (gestures, beliefs, expectations,...) induce, through still-unknown mechanisms, a modulation of therapeutic effects that cannot be explained pharmacologically [74-76]. The emergence of positive

psychology $[77,78]$ studies another implication of semiotics, involving especially the most elaborated functions of the human brain, on the course of human existence.

In accordance with Korzybski's thought, modern cognitive sciences give fundamental importance to the "embodied mind" [79-81]. Numerous interconnections between thought, action and sensory perceptions have been demonstrated, thus breaking the mind-body duality [82-85]. Even language processing is deeply grounded in the body, sharing neural processes with other sensorimotor skills in a context bond phenomenon $[86,87]$. 


\section{The semiotic concept of disarmament and similarities observed}

\section{The Cold War and the expansion of AIDS in western countries}

The Cold War started soon after the second world war and was marked by an arms race, especially nuclear weapons, that put the world under threat of complete annihilation. This period resulted in various tension peaks as the Cuban missiles crisis of 1962. Then began a relaxed period with discussions between the two superpowers. Several armament limitation treaties were signed with the aim of relieving the political tensions and of reducing the risk of nuclear warfare. The different stages of the Cold War and of the nuclear warfare threat were given a lot of media coverage, including various apocalyptic scenarios that fortunately did not arise.

Let us now consider this period and its context from a biological perspective. The nuclear threat of the Cold War constituted a completely new situation for the human race. The risk was of complete annihilation with the inability to either fight or flee. Flight was illusory since no place on the planet was protected from a nuclear conflict or from its consequences. Fight was also impossible since any attack would have almost guaranteed mutual destruction. For ordinary people not implicated in geostrategical decisions, this situation corresponds to a state of complete helplessness. Everyone had a sword of Damocles above his head able to annihilate him at any time. For a huge percentage of ordinary citizens, disarmament was the obvious solution to this horrifying threat. At that time, the concept of disarmament was thus wide-spread, integrated and valuated as THE survival solution.

We notice that for ordinary citizens this learning of the disarmament strategy, that was based on abstract data disconnected from their daily conditions, corresponds to the top-down process described by Korzybski as a source of maladjustment. Did the issue of disarmament and its media coverage induce a conditioning of human beings : conditioning in the Pavlovian sense of conditioned reflexes with the identification of disarmament as a survival strategy in case of extreme tension and risk of annihilation? Due to either confusion about the levels of abstraction or metaphoric thought in the unconscious mind, is this learning implicated at another level of abstraction, that of the immune system, to favor a biological disarmament?

\section{Semiotic context of the emergence of HIV strains at a regional level}

If the semantic similarity between biological disarmament due to AIDS and the nuclear disarmament issue of the Cold War corresponds time-wise with the expansion of the AIDS pandemic in western countries [7], it does not directly correspond with the emergence of AIDS in Africa prior to the second world war. Analysis of the African zones which have been identified as the birthplaces of the different strains of HIV highlights however observations consistent with this semantic similarity. Chitnis [18] describes the sociocultural context of the appearance of HIV-1 in the French colonies of Equatorial Africa. Notably he reports that by 1906 more 
than 50,000 porters, especially slaves, were used every year for head-loading rubber from the country's interior to the coast. He also notes the construction of a railroad from 1899 to 1913, mostly with slave labor. He reports moreover that by the end of the $19^{\text {th }}$ century, the French army in Sudan (mostly in what is today northeastern Guinea and western Mali) made extensive use of slaves for both labor and sex. Life conditions of slaves are well known to have been particularly difficult at this time. Complete submission was imposed on them and any rebellion or attempt to flee was severely punished, often by death. In these conditions, slaves were under the inability to either fight or flee. Their survival depended on their submission to authority and on their renunciation of any attempt to defend themselves. "Suffer passively in order to survive" could define the attitude most favorable to survival in these slavery conditions. Thus and even if the term of disarmament was not coined at that time, disarmament behavior was experienced by the slave populations of this period in this area as the best survival strategy. The semantic similarity described previously can thus be extended to the geographic and temporal appearance of HIV-1.

Since the first HIV-1 able to propagate in humans is dated around $1930( \pm 20$ years $)[5,9]$, either the first host of HIV-1 did experience himself this period as an adult or as a child or his parents did experience it. The emergence of HIV-1 is thus consecutive to this period with a time interval of more or less one generation.

Concerning HIV-2, Poulsen [19] and Lemey [6] observe that the beginnings of the epidemic in Guinea-Bissau coincided with the Independence War (1963-1974) and suggest that the socio-cultural changes linked to the war had a major impact on the HIV-2 epidemic. It is obvious that in war conditions, the renunciation of violence (the disarmament concept) is deeply desired by a significant part of the civil population.

We thus observe that for the birthplaces of HIV-1 and HIV-2, the semantic concept of disarmament is actually concomitant to the development of the pandemic in a period of intense stress (slavery, war). This observation is supplementary to specific conditions, favorable to the propagation of HIV and already reported by these authors (non-sterile vaccination campaigns, sexuality, hunting,...).

\section{Interpretation and prospects}

\section{Hypothesis of a collusion by the neuro-immune system in AIDS}

The observations reported until now highlight a striking similarity centered on the semiotic concept of disarmament. On one hand, disarmament was the best survival strategy experienced or learned as a response to an intense socio-environmental stress (slavery, Cold War). On the other hand, disarmament describes perfectly the main physiological effect of AIDS on the human organism. A fundamental difference between these two kinds of disarmament has however to be noticed : 
Disarmament directed outwards : In the case of geostrategical disarmament or for the submission behavior of slaves towards their masters, disarmament is directed outwards. It consists of the repression of defense impulses and of passively enduring extremely difficult life conditions. In this case, this attitude is positive and favorable to survival.

Disarmament directed inwards : In the case of biological disarmament, the effects are produced physiologically inside the organism. Immune deficiency leaves the body disarmed and unable to resist non-self aggressions. This renunciation of aggressiveness leads to disease and death. It is negative and unfavorable to survival.

These two kinds of disarmament, respectively behavioral and physiological, lead to clearly opposed effects and it is difficult to think of a confusion between them; especially among scientists who historically apprehend behavior and physiology as almost distinct issues. For the unconscious mind however, behavior and physiology are two facets of unique actions, as when physiological regulations are adequately tuned for supplying sharp behavioral needs as for instance in case of fight or flight. Furthermore, the unconscious mind processes are known to involve metaphoric thought and conceptual blending and to be subject to confusion of levels of abstraction. Embodied cognition has also been demonstrating that language and its understanding is shortly related to the neural networks allowing action. A confusion of these two classes of disarmament by the unconscious mind is thus plausible, especially in case of intense stress. Thus, as psychosocial stress is known to trigger physiological pathologies [88], and as conditioning is able to control behavior and physiology [22], it is natural to wonder if this semiotic similarity hides an actual cause-and-effect relationship? The question is thus to determine whether this similarity is caused by chance or if it results from some collusion by the organism? Such a collusion would demonstrate the existence of a semiotic mechanism of unconscious adjustment to stress that is specific to humans whose brain development provides enormous capabilities of both conscious and unconscious cognitive processes in close connection with sensory perceptions. The facts reported in this paper do not provide any evidence of the existence of such a semiotic mechanism. However, the reported similarity is striking enough to justify the scientific consideration of such a hypothesis that could be expressed thus :

The infection by HIV and the disease development benefit from some degree of collusion by the neuro-immune system of the host. This collusion responds to a learned disarmament strategy and is set by the unconscious mind of the individual in reaction to an intense stress. This stress is perceived by the unconscious cognitive system as an extreme tension with the inability to either fight or flee. The application of this strategy at the level of the immune system results from an improper abstraction by the unconscious cognitive system. This unconscious mechanism makes the "terrain" favorable to the "germ".

From this perspective, the 30 million deaths caused by AIDS exhibit natural selection in action which demonstrates the failure of this maladaptive strategy. 
The effects of stress have been studied for a long time and numerous consequences have already been identified in individuals that suffer it as well as in their descendants. The only novelty of this collusion hypothesis is to introduce a semantic rationality in the cause-and-effect mechanism. This hypothesis means that intense stress may trigger unconscious adjustments determined by the semantic nature of the stress as perceived by the individuals. The delays between the socio-environmental events considered above and the emergence of the HIV strains in Africa and the propagation of AIDS in western countries are not known precisely but necessarily shorter than fifty years. This time range is compatible with the hypothesis of an effect of stress, for instance because of exposure during the development stage or by transgenerational transmission of epigenetic programs as discussed previously. Since such a mechanism would involve some collusion by the organism, it may be considered as a Lamarkian adaptation attempt to deal with the environmental pressure experienced.

One may notice that the similarity reported above and centered on the disarmament strategy agrees with the thought of founding fathers of biology as Dobzhansky, Lorenz and Laborit: "Nothing in biology makes sense except in the light of evolution". [89] "The gain in knowledge, achieved by trial and error by the genome - which retains what is the fittest for it - results in the formation of an image of the material world within the living system; an image "built up", as D.M. Mackay puts it, from the "descriptive information content of the situation". The image thus formed is, in a way, a negative of reality, like a photographic negative, or the plaster cast of a coin" [90]. "All dichotomy between man and his environment, between the psychic and the somatic, seems to hark back to some prehistoric era of biology, to a time when thermodynamics dominated scientific research and a formal notion of information did not yet exist" [91].

\section{Conditions of existence of such a semiotic mechanism}

At this point, the collusion hypothesis discussed above remains an abstract scenario. This section aims to elucidate under which conditions such a semiotic mechanism could exist and if these conditions fit the current acceptation of the functioning of the human body.

\section{The role of the nervous system}

Such a mechanism would be based on the unconscious perception of our environment and more particularly on the semantic nature of the stress experienced. This requirement that corresponds exactly to the main function of the nervous system - to perceive (inside and outside) - is fulfilled.

Such a mechanism would also assume some confusion of the abstraction levels in our unconscious cognitive system for inducing a loss of differentiation between actions directed towards the world outside the body (disarmament, submission) and towards the world inside the body (immune deficiency). Such a confusion corresponds to the description by Korzybski [21] on the confusion of the levels of abstraction as well as with modern cognition 
science that elucidated unconscious processes as integration, metaphoric thought and conceptual mixing $[79,80] \ldots$

The implication of the brain in a collusion mechanism is also consistent with the scientific context described in the recent advances section for issues concerning the impact of stress on the brain, the roots of disease and the heredity of epigenetic programs.

\section{The signaling potential of biological constituents}

In the case of the cross-species transmission to humans of simian viruses evolving towards the different HIV strains, we note that the semantic observations provide a plausible answer to the question of why there were so many cross-species transmissions during the only $20^{\text {th }}$ century. However, to link the evolution of SIVs into HIVs to the semantic context would have radically new biological implications. This would imply that the neuro-immune system of the host is party to its own infection by the virus. This collusion would be justified by a new functionality capable of implementing at the physiological level an immune disarmament behavior. This perspective would thus attribute an active and permissive role to the neuro-immune system in the HIV infection that does not correspond to the current synthesis.

This collusion of the neuro-immune system would assume that the entering immunodefficiency virus is initially assessed for its functional potential; i.e. its ability to behave as an "immune disarmament operator" by the neuro-immune system. This would confer to the bio-molecular structure of the virus an identity carrying the label : "immune disarmament operator", this label being detectable by the host neuro-immune system. This condition consists of attributing to biological constituents a kind of signal - organic structure duality similar to the wave - particle duality known in physics. Again, this hypothesis is radically different from the current scientific consensus. We note however that signals are key elements of the regulation mechanisms that ensure the functioning of living organisms. Numerous reactions are indeed controlled by the concentration of different constituents (ions, hormones, messenger RNA, neuro-transmitters,...) that act as a number of internal state and/or command signals. The cybernetic approach [92] of living beings and their dysfunctions remains poorly explored, probably because of the difficulties in collecting the huge amount of relevant data for each individual.

\section{Evaluating the collusion hypothesis}

The hypothesis that AIDS is a biological disarmament state benefiting from some unconscious collusion of the neuro-immune system is based on well-defined semantic notions such as identity (self), otherness (non-self), territory (body), aggressiveness (immune defenses) and its repression (immune deficiency). If the unconscious cognitive system is implicated in AIDS, the relationship of individuals with these semantic notions might also be affected. A comparative psychological study of a group of people affected by AIDS with a control group would allow the search for differences in the relationship of these populations to these semantic notions linked to 
immunity. A similar comparative study could be based on functional magnetic resonant imaging of the brain by choosing discriminating stimuli with respect to these semantic notions. Automated language processing would provide yet another approach for the search of such differences at a language level. The proposed analysis consists simply of looking for a systemic coherence at the level of the organism-as-a-whole in its environment with respect to these semantic notions related to AIDS.

Korzybski [21] emphasizes the importance of being conscious of the many levels of abstraction allowed by our central nervous system in order that in each context, the individual identifies and uses the proper level of abstraction. For individuals affected by AIDS, this would consist of the clear discrimination of the two kinds of disarmament concepts, respectively behavioral or physiological; i.e. directed outwards or directed inwards. Since the cognitive system is implicated in this hypothesis through improper metaphoric thought and/or conceptual mixing between these two types of disarmament, the conscious learning of this distinction would provide a possibility for readjustment of the cognitive system. Such readjustment would only occur if a semantic continuity takes place spontaneously between the conscious and unconscious levels of the mind. In the case of denial of pregnancy, it was observed that the integration of a piece of information can be sufficient to trigger a spontaneous recovery at the physiological level [93].

In our analysis, the disarmament concept was considered within the particular contexts of the Cold War and of the conditions of slaves in Africa. We may observe that this concept can be found in many different guises in modern society. For instance, the instructions given to bank employees in the event of gun attacks recommend them to renounce resistance, to comply with the gangster's commands and thus to increase the chance of safe escape from danger. These instructions are essentially another form of disarmament behavior. This concept also suits the behavior of people who passively suffer the oppression of a relative or of a boss because of the threat to the familial or the professional relationship. Thus, even if the learning of the disarmament behavior was collective through the media coverage of various stages of the Cold War, the personal context of each individual has to be considered to account for the unique space-time nature of empirical facts as described by Korzybski.

\section{Conclusion}

On the basis of semantic similarities observed in the socio-environmental context prior to the emergence and propagation of the disease, this paper presents the hypothesis that AIDS may involve some collusion by the neuro-immune system because of positive learning of the disarmament strategy. This semiotic mechanism would be specific of the cognitive abilities of humans. The consideration of this hypothesis within a multidisciplinary context and with respect to current biological knowledge leads to contrasted results. On the one hand, the existence of such a mechanism would require that very early after infection, the HIV virus can be functionally 
identified by the neuro-immune system as a disarmament operator. This condition would associate informational properties to biological constituents that are far from the current acceptation. On the other hand, this hypothesis appears plausible in regards to the ability of signs to control behavior and physiology, current cognition sciences and recent evidence of the transmission of epigenetic programs. This multidisciplinary context is however too general to allow definitive conclusions in the specific case considered here.

Further research at the systemic level of the individual is proposed for elucidating the existence - or nonexistence - of such a collusion by the neuro-immune system. These investigations are particularly important since if such a mechanism was confirmed in the case of AIDS, it may concern other human dysfunctions through the same kind of mismatched semiotic identification and offer supplementary, cognition-based, therapeutic prospects. Successful adaptation attempts can also been thought of thanks to this mechanism in the case of well-matched semiotic identifications. The physiological needs necessary for the development and the functioning of the human nervous system are highly significant [94,95]. The human nervous system was however naturally selected during human evolution. This success means that the adaptive advantages provided by the human nervous system are at least as significant as its physiological cost. These adaptive advantages are still not definitely understood. If the existence of such a semiotic mechanism was confirmed, it would correspond to an actual contribution of our brain to the unconscious adaptation processes of humans to the environment pressure experienced. This contribution would be compatible with the widely accepted view of the social brain hypothesis [95]. We note indeed that the socio-environmental stressful events considered in this paper correspond actually to social issues.

While waiting for further research to evaluate this hypothesis, the following citations show that the existence of such a Lamarkian mechanism in humans bodes well with respect to the thoughts of such founding fathers of modern biology as Darwin and Selye respectively :

"I have hitherto sometimes spoken as if the variations... had been due to chance. This, of course, is a wholly incorrect expression, but it serves to acknowledge plainly our ignorance of the cause of each particular variation... [The observations] lead me to believe that deviations of structure are in some way due to the nature of the conditions of life, to which the parents and their more remote ancestors have been exposed during several generations. I have remarked that the reproductive system is eminently susceptible to changes in the conditions of life; and to this system being functionally disturbed in the parents, I chiefly attribute the varying or plastic condition of the offspring. The male and female sexual elements seem to be affected before that union takes place which is to form a new being." [96].

"The fact remains, however, that all experimental observations are most readily compatible with the view that during the general adaptation syndrome, certain hormones of the anterior pituitary and adrenal cortex are produced in excessive amounts in order to increase resistance; this defensive endocrine response is valuable in as much as it facilitates adaptation to stress, but the resulting endogenous hormone overdosage may become 
the cause of certain cardiovascular, renal and joint diseases. Thus developed the concept that many of the most common maladies of man are "diseases of adaptation", that is to say, the by-products of abnormal adaptive reactions to stress." [97].

\section{Conflict of interest}

The author of this paper does not have any conflict of interest concerning this work.

\section{Références}

1. Barré-Sinoussi F, Chermann JC, Rey F, Nugeyre MT, Chamaret S, et al., Isolation of a T-lymphotropic retrovirus from a patient at risk for acquired immune deficiency syndrome (AIDS). Science $1983 ; 220(4599)$ : 868-871.

2. Gallo RC, Sarin PS, Gelmann EP, Robert-Guroff M, Richardson E, et al., Isolation of human T-cell leukemia virus in acquired immune deficiency syndrome (AIDS). Science $1983 ; 220(4599)$ : 865-867.

3. Zhu T, Korber BT, Nahmias AJ, Hooper E, Sharp PM, et al., An African HIV-1 sequence from 1959 and implications for the origin of the epidemic. Nature 1998 ;391(6667) : 594-597.

4. Worobey M, Gemmel M, Teuwen DE, Haselkorn T, Kunstman K, et al., Direct evidence of extensive diversity of HIV-1 in Kinshasa by 1960. Nature 2008 ;455(7213) : 661-664.

5. Korber B, Muldoon M, Theiler J, Gao F, Gupta R, et al., Timing the ancestor of the HIV-1 pandemic strains. Science $2000 ; 288(5472): 1789-1796$.

6. Lemey P, Pybus OG, Wang B, Saksena NK, Salemi M, et al., Tracing the origin and history of the HIV-2 epidemic. Proc Natl Acad Sci U S A 2003 ;100(11) : 6588-6592.

7. Gilbert MTP, Rambaut A, Wlasiuk G, Spira TJ, Pitchenik AE, et al., The emergence of HIV/AIDS in the Americas and beyond, Proc Natl Acad Sci U S A 2007 ;104(47) : 18566-18570.

8. Wertheim JO, Worobey M, Dating the age of the SIV lineages that gave rise to HIV-1 and HIV-2. PLoS Comput Biol $2009 ; 5(5)$ : e1000377.

9. Castro-Nallar E, Pérez-Losada M, Burton GF, Crandall KA, The evolution of HIV : Inferences using phylogenetics. Mol Phylogenet Evol $2012 ; 62$ : 777-792.

10. Hahn BH, Shaw GM, De KM, Sharp PM, AIDS as a zoonosis : scientific and public health implications. Science $2000 ; 287(5453)$ : 607-614.

11. Keele BF, Van Heuverswyn F, Li Y, Bailes E, Takehisa J, et al., Chimpanzee reservoirs of pandemic and nonpandemic HIV-1. Science 2006 ;313(5786) : 523-526. 
12. de Sousa JD, Müller V, Lemey P, Vandamme AM, High GUD Incidence in the Early 20th Century Created a Particularly Permissive Time Window for the Origin and Initial Spread of Epidemic HIV Strains. PloS one $2010 ; 5(4)$ : e9936.

13. Locatelli S, Peeters M, Cross-species transmission of simian retroviruses : how and why they could lead to the emergence of new diseases in the human population. AIDS $2012 ; 26(6): 659-673$.

14. Gao F, Bailes E, Robertson DL, Chen Y, Rodenburg CM, et al., Origin of HIV-1 in the chimpanzee Pan troglodytes troglodytes. Nature $1999 ; 397(6718)$ : 436-440.

15. Marx PA, Apetrei C, Drucker E, AIDS as a zoonosis? Confusion over the origin of the virus and the origin of the epidemics. J Med Primatol $2004 ; 33(5-6)$ : 220-226.

16. Worobey M, Telfer P, Souquière S, Hunter M, Coleman CA, et al., Island biogeography reveals the deep history of SIV. Science $2010 ; 329(5998)$ : 1487.

17. Chen Z, Telfier P, Gettie A, Reed P, Zhang L, et al., Genetic characterization of new West African simian immunodeficiency virus SIVsm : geographic clustering of household-derived SIV strains with human immunodeficiency virus type 2 subtypes and genetically diverse viruses from a single feral sooty mangabey troop. J Virol $1996 ; 70(6)$ : 3617-3627.

18. Chitnis A, Rawls D, Moore J, Origin of hiv type 1 in colonial french equatorial africa? AIDS Res Hum Retroviruses $2000 ; 16(1): 5-8$.

19. Poulsen AG, Aaby P, Jensen H, Dias F, Risk factors for HIV-2 seropositivity among older people in Guinea-Bissau. A search for the early history of HIV-2 infection. Scand J Infect Dis $2000 ; 32(2)$ : 169-175.

20. Engel GL, The need for a new medical model : a challenge for biomedicine. Science $1977 ; 196: 4286$ 129-136.

21. Korzybski A, Science and sanity : An introduction to non-Aristotelian systems and general semantics. 1933; (Intern. non-aristotelician library $3^{\text {rd }}$ ed., 1948).

22. Pavlov IP, Anrep GV, Conditioned reflexes. (Dover Pubns, 2003).

23. Apfelbach R, Blanchard CD, Blanchard RJ, Hayes RA, McGregor IS, The effects of predator odors in mammalian prey species : a review of field and laboratory studies. Neurosci Biobehav Rev $2005 ; 29: 8$ $1123-1144$.

24. Levine GF, Learned helplessness and the evening news. J commun $1977 ; 27: 4,100-105$.

25. Gerbner G, Telling All the Stories : Children and Television. Sacred Heart Univ Rev $1996 ; 16$ : 1, 36-54.

26. Rizzolatti G, Craighero L, The mirror-neuron system. Annu Rev Neurosci $2004 ; 27$ : 169-192. 
27. Iacoboni M, Molnar-Szakacs I, Gallese V, Buccino G, Mazziotta JC, Rizzolatti G, Grasping the intentions of others with one's own mirror neuron system. PLoS biol $2005 ; 3: 3$ e79.

28. Mukamel R, Ekstrom AD, Kaplan J, Iacoboni M, Fried I, Single-neuron responses in humans during execution and observation of actions. Curr Biol $2010 ; 20: 8$ 750-756.

29. Korzybski A, The role of language in the perceptual processes. In : Blake RR, Ramsey GV, editors. Perception : An approach to personality. (Ronald Press Comp. 1951, 170-205).

30. Huxley J, Evolution. The Modern Synthesis. (Harper \& brothers 1943).

31. Holliday R, The inheritance of epigenetic defects. Science $1987 ; 238(4824)$ : 163-170.

32. Fraga MF, Ballestar E, Paz MF, Ropero S, Setien F, et al., Epigenetic differences arise during the lifetime of monozygotic twins. Proc Natl Acad Sci U S A 2005 ;102(30) : 10604-10609.

33. Rando OJ, Verstrepen KJ, Timescales of genetic and epigenetic inheritance. Cell $2007 ; 128(4)$ : 655-668.

34. Richards EJ, Inherited epigenetic variation - revisiting soft inheritance. Nat Rev Genet $2006 ; 7(5)$ : 395401.

35. Shea N, Pen I, Uller T, Three epigenetic information channels and their different roles in evolution. J Evol Biol $2011 ; 24(6)$ : $1178-1187$.

36. Jablonka E, Lamb MJ, Soft inheritance : challenging the modern synthesis. Genet Mol Biol $2008 ; 31(2)$ : 389-395.

37. Harper L, Epigenetic inheritance and the intergenerational transfer of experience. Psychol Bull $2005 ; 131(3)$ : 340-360.

38. Jablonka E, Raz G, Transgenerational epigenetic inheritance : prevalence, mechanisms, and implications for the study of heredity and evolution. Q Rev Biol 2009 ;84(2) : 131-176.

39. Youngson NA, Whitelaw E, Transgenerational epigenetic effects. Annu Rev Genomics Hum Genet $2008 ; 9$ : 233-257.

40. Whitelaw NC, Whitelaw E, Transgenerational epigenetic inheritance in health and disease. Curr Opin Genet Dev $2008 ; 18(3): 273-279$.

41. Daxinger L, Whitelaw E, Transgenerational epigenetic inheritance : More questions than answers. Genome Res $2010 ; 20(12): 1623-1628$.

42. Franklin TB, Russig H, Weiss IC, Gräff J, Linder N et al., Epigenetic transmission of the impact of early stress across generations. Biol Psychiatry $2010 ; 68(5)$ : 408-415.

43. Jirtle RL, Skinner MK, Environmental epigenomics and disease susceptibility. Nat Rev Genet $2007 ; 8(4)$ : 253-262. 
44. Robinson GE, Grozinger CM, Whitfield CW, Sociogenomics : social life in molecular terms. Nat Rev Genet $2005 ; 6(4): 257-270$.

45. Aguilera O, Fernández AF, Muñoz A, Fraga MF, Epigenetics and environment : a complex relationship. J Appl Physiol 2010;109(1) : 243-251.

46. Champagne FA, Mashoodh R, Genes in context : Gene-environment interplay and the origins of individual differences in behavior. Curr Dir Psychol Sci $2009 ; 18(3)$ : 127-131.

47. Szyf M, McGowan P, Meaney MJ, The social environment and the epigenome. Environ Mol Mutagen $2008 ; 49(1): 46-60$.

48. Anway MD, Cupp AS, Uzumcu M, Skinner MK, Epigenetic transgenerational actions of endocrine disruptors and male fertility. Science $2005 ; 308(5727)$ : 1466-1469.

49. Zama AM, Uzumcu M, Epigenetic effects of endocrine-disrupting chemicals on female reproduction : An ovarian perspective. Front Neuroendocrinol $2010 ; 31(4)$ : 420-439.

50. Crews D, Gore AC, Hsu TS, Dangleben NL, Spinetta M et al., Transgenerational epigenetic imprints on mate preference. Proc Natl Acad Sci U S A $2007 ; 104(14)$ : 5942-5946.

51. Masterpasqua F, Psychology and epigenetics. Rev Gen Psychol 2009 ;13(3) : 194-201.

52. Champagne FA, Epigenetic mechanisms and the transgenerational effects of maternal care. Front Neuroendocrinol $2008 ; 29(3): 386-397$.

53. Jablonka E, Epigenetic epidemiology. Int J Epidemiol 2004 ;33(5) : 929-935.

54. Feinberg AP, Phenotypic plasticity and the epigenetics of human disease. Nature 2007 ;447(7143) : 433440.

55. Dolinoy DC, Weidman JR, Jirtle RL, Epigenetic gene regulation : linking early developmental environment to adult disease. Reprod Toxicol $2007 ; 23(3)$ : 297-307.

56. Tang W, Ho S, Epigenetic reprogramming and imprinting in origins of disease. Rev Endocr Metab Disord $2007 ; 8(2): 173-182$.

57. Whitelaw NC, Whitelaw E, How lifetimes shape epigenotype within and across generations. Hum Mol Genet $2006 ; 15($ suppl 2) : R131-R137.

58. Godfrey KM, Lillycrop KA, Burdge GC, Gluckman PD, Hanson MA, Epigenetic mechanisms and the mismatch concept of the developmental origins of health and disease. Pediatr Res 2007;61(5 Part 2) : 5R-10R.

59. Feinberg AP, Epigenetics at the epicenter of modern medicine. JAMA $2008 ; 299(11)$ : 1345-1350.

60. Esteller M, Epigenetics in cancer. N Engl J Med Overseas Ed $2008 ; 358(11)$ : 1148-1159. 
61. Gillman MW, Developmental origins of health and disease. N Engl J Med Overseas Ed 2005 ;353(17) : $1848-1850$.

62. Hanson MA, Gluckman PD, Developmental origins of health and disease : new insights. Basic Clin Pharmacol Toxicol $2008 ; 102(2): 90-93$.

63. Ader R, Cohen N, Felten D, Psychoneuroimmunology : interactions between the nervous system and the immune system. Lancet $1995 ; 345(8942)$ : 99-103.

64. Zachariae R, Psychoneuroimmunology : A bio-psycho-social approach to health and disease. Scand J Psychol $2009 ; 50(6)$ : 645-651.

65. Mifsud KR, Gutièrrez-Mecinas M, Trollope AF, Collins A, Saunderson EA, et al., Epigenetic mechanisms in stress and adaptation. Brain Behav Immun $2011 ; 25$ : 1305-1315.

66. Joëls M, Baram TZ, The neuro-symphony of stress. Nat Rev Neurosci $2009 ; 10(6)$ : 459-466.

67. Shonkoff JP, Boyce WT, McEwen BS, Neuroscience, molecular biology, and the childhood roots of health disparities. JAMA 2009 ;301(21) : 2252-2259.

68. Hüther G, The central adaptation syndrome : psychosocial stress as a trigger for adaptive modifications of brain structure and brain function. Prog Neurobiol 1996 ;48(6) : 569-612.

69. McEwen BS, Gianaros PJ, Central role of the brain in stress and adaptation : links to socioeconomic status, health, and disease. Ann N Y Acad Sci $2010 ; 1186(1)$ : 190-222.

70. Salovey P, Rothman AJ, Detweiler JB, Steward WT, Emotional states and physical health. Am Psychol $2000 ; 55(1): 110-121$.

71. Belsky J, Conger R, Capaldi DM, The intergenerational transmission of parenting : Introduction to the special section. Dev Psychol 2009 ;45(5) : 1201-1204.

72. Schützenberger AA, The ancestor syndrome : transgenerational psychotherapy and the hidden links in the family tree. (Routledge 1998).

73. Noriega G, Transgenerational scripts : the unknown knowledge. in Life Scripts : A Transactional Analysis of Unconscious Relational Patterns. (Erskine RG, editors Karnac Books. 2010 ;p.269-290).

74. Enck P, Benedetti F, Schedlowski M, New insights into the placebo and nocebo responses. Neuron $2008 ; 59(2): 195-206$.

75. Benedetti F, Pollo A, Lopiano L, Lanotte M, Vighetti S et al., Conscious expectation and unconscious conditioning in analgesic, motor, and hormonal placebo/nocebo responses. J Neurosci 2003 ;23(10) : 43154323. 
76. Hahn RA, The nocebo phenomenon : concept, evidence, and implications for public health. Prev Med $1997 ; 26(5): 607-611$.

77. Seligman MEP, Csikszentmihalyi M, Positive psychology : An introduction, Am Psychol 2000 ;55(1) : $5-14$.

78. Taylor SE, Kemeny ME, Reed GM, Bower JE, Gruenewald TL, Psychological resources, positive illusions, and health. Am Psychol $2000 ; 55(1)$ : 99-109.

79. Lakoff G, Johnson M, Philosophy in the flesh : The embodied mind and its challenge to western thought (Basic Books 1999).

80. Fauconnier G, Turner M, The way we think : Conceptual blending and the mind's hidden complexities. (Basic Books 2003).

81. Thelen E, Time-scale dynamics and the development of an embodied cognition, in : Mind as motion : Explorations in the dynamics of cognition, (Port, R.F. \& Van Gelder, T., eds., the MIT press 1995 ;p.69100).

82. Chiel HJ, Beer RD, The brain has a body : Adaptive behavior emerges from interactions of nervous system, body and environment, Trends Neurosci $1997 ; 20(12), 553-557$.

83. Barsalou LW, Grounded cognition, Annu Rev Psychol 2008 ;59, 617-645.

84. Grafton ST, Embodied cognition and the simulation of action to understand others, Ann NY Acad Sci $2009 ; 1156(1), 97-117$.

85. Borghi AM, Cimatti F, Embodied cognition and beyond : Acting and sensing the body, Neuropsychologia $2010 ; 48(3), 763-773$.

86. Pulvermüller F, Brain mechanisms linking language and action, Nat Rev Neurosci $2005 ; 6(7), 576-582$.

87. Van Elk M, Slors M, Bekkering H, Embodied language comprehension requires an enactivist paradigm of cognition, Front Psychol $2010 ; 1,234$.

88. Caso JR, Leza JC, Menchen L, The effects of physical and psychological stress on the gastrointestinal tract : lessons from animal models. Curr Mol Med $2008 ; 8(4)$ : 299-312.

89. Dobzhansky T, Nothing in biology makes sense except in the light of evolution. Am Biol Teach $1973 ; 35(3)$ : 125-129.

90. Lorenz K, Behind the mirror : A search for a natural history of human knowledge. (Methuen \& Co Ltd. $1977 ;$ p.23).

91. Laborit H, L'inhibition de l'action (Masson 1979). 
92. Wiener N, Cybernetics, or Control and Communication in the Animal and the Machine (Technol Press $1948 ;$ p.232).

93. Sandoz P, Reactive-homeostasis as a cybernetic model of the silhouette effect of denial of pregnancy. Med Hypotheses $2011 ; 77(5): 782-785$.

94. Dunbar RIM, Shultz S, Understanding primate brain evolution, Phil Trans R Soc Lond, B, Biol Sci $2007 ; 362(1480), 649-658$.

95. Dunbar RIM, Shultz S, Evolution in the social brain, Science 2007 ;317(5843), 1344-1347.

96. Darwin C, On the origin of species by means of natural selection (1859; Dover $3^{\text {rd }}$ ed. 2006 ;p.83).

97. Selye H, The general adaptation syndrome and the diseases of adaptation. J Clin Endocrinol $1946 ; 6(2)$ : $117-230$. 